\title{
LIDERANÇA DA ENFERMEIRA NA PERSPECTIVA DAÉTICA PÓS-MODERNA
}

\author{
NURSE'S LEADERSHIP IN THE PERSPECTIVE OF POSTMODERN \\ ETHICS \\ LIDERAZGO DE LA ENFERMERA EN LA PERSPECTIVA DE LA ÉTICA \\ POSMODERNA
}

\author{
Isabel Amélia Costa Mendes ${ }^{1}$ \\ Maria Auxiliadora Trevizan ${ }^{1}$ \\ Clarice Aparecida Ferraz ${ }^{2}$ \\ Miyeko Hayashida ${ }^{3}$
}

\begin{abstract}
RESUMO: Os enfoques administrativos oriundos da modernidade estão, cada vez mais, se tornando obsoletos face às necessidades das organizações, sobretudo, daquelas prestadoras de serviços como é o caso das instituições de saúde; bem como de seu capital humano. Sendo a racionalidade o elemento essencial na consecução dos objetivos organizacionais, a ética moderna exige apenas que os trabalhadores se ajustem aos cargos descritos e às normas de desempenho no cumprimento de suas tarefas. A pós-modernidade é caracterizada pela saturação de informação e consumo, pelo prazer de usar bens e serviços, pela ausência de valores e de sentido para a vida, refletindo a apatia pós-moderna. Sem projetos, a vida interior do homem é sem substância. As organizações de saúde estão sofrendo fortes influências deste contexto. Nesse sentido, a ética precisa ser tratada de maneira nova. Assim sendo, nosso propósito é abordar a liderança da enfermeira à luz da ética pós-moderna.
\end{abstract}

PALAVRAS-CHAVE: liderança, ética, conhecimento, estética, cultura organizacional

A rigorosa utilização da ciência na organização do trabalho e no processo produtivo, a racionalização excessiva, a divisão social do trabalho e seu fracionamento técnico, a conjugação do homem à máquina, a valorização dos critérios de eficiência e produtividade tendo em vista a otimização dos recursos e dos meios de produção, a crença que fundamenta a eficiência ao one best way, a presença de conflitos entre empregados e empregadores, etc. são, sumariamente, as características da organização da sociedade industrial que floresceu no período moderno. Essa visão significou o estabelecimento de uma ordem social dinâmica, orientada pela razão, na busca frenética do progresso econômico e tecnológico, não levando em conta as particularidades e a totalidade do trabalhador enquanto pessoa que incorpora crenças e valores diferentes daqueles predominantes na sociedade moderna

Para Capra (1995) quanto mais se examina os problemas sociais desse tempo, mais se percebe que " a visão mecanicista do mundo e o sistema de valores que the está associado geraram tecnologia, instituições e estilos de vida profundamente patológicos" (Capra, 1995, p.253).

No campo da gestão, uma das conseqüências da revolução industrial foi a modernização

\footnotetext{
${ }_{1}$ Pesquisador 1-A CNPq e Professor Titular da Escola de Enfermagem de Ribeirão Preto-USP.

2 Professor Doutor da Escola de Enfermagem de Ribeirão Preto-USP.

${ }^{3}$ Doutora em Enfermagem Chefe da Seção de Apoio Laboratorial - Escola de Enfermagem de Ribeirão Preto da USP, Centro Colaborador da OMS para o Desenvolvimento da Pesquisa em Enfermagem - Brasil.
} 
administrativa e gerencial, iniciada através dos pressupostos de Taylor sobre gerência científica, a partir da transição do século XIX para o século XX. O momento e o movimento da gerência científica são amplamente expostos e criticados na literatura da área. Nessa esfera de atividades surgiram várias tendências, outros modelos, dentre os quais o modelo burocrático de Weber, que contribuíram para a performance dos valores modernos na gerência.

Apesar do impulso em termos tecnológicos, organizacionais e administrativos, obtendo melhorias e vantagens significativas na produção de bens e na prestação de serviços, causando alterações expressivas na qualidade de vida, a modernidade, segundo Motta (1997), apresentou resultado incompleto e injusto pois, além de servir apenas a uma pequena parcela da humanidade, acentuaram-se as desigualdades entre os povos. Ainda, ao exacerbar a racionalidade econômica e material como fatores determinantes do progresso, a modernidade com suas propostas pragmáticas e utilitárias atuou em descompasso com os valores da solidariedade, da espiritualidade e da sobrevivência da terra.

Ao tratar da episteme da modernidade Ferraz (1995) comenta que cada época é caracterizada pelo seu sistema de organização social, congregando valores que orientam e modelam as práticas cotidianas nos diversos domínios e, na realidade, quase que impossibilitam os indivíduos de atuarem à margem das intenções dominantes.

Desta forma, as instituições de saúde e a organização do trabalho na enfermagem também se renderam às leis da racionalidade que direcionaram a modernidade. Em nosso meio, ainda constatamos a vigência marcante da herança de Taylor e de Weber no gerenciamento das organizações de enfermagem. Essas organizações têm privilegiado o como fazer em detrimento porquê da ação, de forma que a eficiência tem se alicerçado, quase que exclusivamente, na racionalidade em busca da eficácia, priorizando os objetivos e as finalidades do serviço. Neste contexto, uma das exigências da ética moderna é que os trabalhadores se ajustem aos cargos descritos e às normas de desempenho no cumprimento de suas tarefas. Assim sendo, seus enfoques administrativos estão, cada vez mais, se tornando obsoletos face as novas exigências da sociedade atual, ou seja, a sociedade pós-moderna.

\section{A ÉPOCA PÓS - MODERNA}

A mudança da sociedade industrial para a sociedade pós-moderna ou sociedade pósindustrial, segundo De Masi $(1999,2000)$ é determinada pelos seguintes fatores: o progresso técnico-científico, com destaque para a tecnologia eletrônica e a biotecnologia; a incorporação de novas lógicas nas inovações tecnológicas; o processo organizacional e a globalização.

Argumenta o autor que na fase que estamos enfrentando compartilha-se a consciência de que os paradigmas que nortearam nosso passado são insuficientes para explicar o presente e antecipar o futuro. Adicionalmente, a sufocante sensação de crise desenvolveu a necessidade de um novo modelo conceitual, um novo paradigma, isento das insuficiências dos anteriores. A travessia de uma fase para outra não implica em substituição total da anterior, mas significa a centralidade de um elemento em detrimento do outro, " que perde a hegemonia mas não a presença e influência" (De Masi, 2000, p.167).

De Masi (2000) considera a legitimidade de se inferir que a sociedade pós-moderna não estará mais sustentada num único setor, mas estará descentralizada numa pequena rede de setores no mesmo nível de importância - a informação, a ciência, os serviços, a própria industria; por isso, o autor alerta para a necessidade de se concentrar esforços para identificar, interpretar e dirigir a nova realidade.

Nesta sociedade, o conhecimento ocupa uma posição central. Se na era industrial o processo organizacional se desenvolvia segundo uma lógica própria, na era atual assistimos a " hibridização das várias lógicas organizativas" (De Masi, 1999,p.183) - a capacitação gerencial torna-se articuladora entre a lógica organizacional e as do mundo exterior. 
Na sociedade industrial predominava a racionalização inflexível; já na organização póstaylorista e pós-fordiana, segundo De Masi (2000), há a conjugação máxima racionalidade com a máxima flexibilidade que, em sinergia com precisão, segurança, beleza e rapidez constituem " um novo paradigma de organização, em que as visões gerencial, política e até estética da empresa terminam se encontrando" (De Masi, 2000, p.184) possibilitando o despontar da criatividade, da conectividade e de novas formas de convívio.

Por sua vez, as conseqüências da globalização refletem-se nas relações sociais e econômicas, na organização do trabalho e no contexto político. Na visão de De Masi (2000) o consumo ganha posição de relevo na globalização que, paradoxalmente, nutre uma profunda subjetividade que rejeita a massificação, o consumismo, para privilegiar formas de vida mais discretas. Salienta que enquanto a globalização gera resultado homologador, a sociedade se fragmenta em sub-grupos, cada qual centrado no seu modo de viver, na sua profissão, na sua ideologia e na sua região - é uma condição unificada e fragmentada.

Nesta época, os trabalhadores incorporam o saber, interferindo nas decisões organizacionais - assim agindo, eles estarão determinando seu futuro.

Dentre os valores emergentes da nova sociedade, estão aqueles conectados à intelectualização das atividades humanas, requerendo criatividade e preparo cultural; a confiança e a ética - indispensáveis nos serviços que requerem qualidade e confiabilidade; o estético, que pressupõe que o serviço, além de cumprir seu objetivo prático, atenda aos quesitos de refinamento, originalidade e beleza; a subjetividade que indica a necessidade de afirmar as particularidades que nos diferenciam do outro; emoção e afeto - a esfera emotiva e afetiva foi negada face ao racionalismo excessivo. Hoje é indispensável a contribuição criativa do trabalhador e a criatividade é fruto da síntese das esferas racional e emotiva; desta forma, se a organização pós-moderna quiser ser criativa deve resgatar a emotividade. Enfim, todos esses valores têm em perspectiva compor a qualidade de vida buscada pelo homem na era pós - moderna.

A nova referência entre sociedade e organização incita uma transformação dos valores organizacionais. A emergente sociedade pós-moderna, que se movimenta sob a conexão e a reintegração de trabalho e vida, em suas várias dimensões, está afetando o mundo das organizações. Além de se caracterizar pela prestação de serviços à saúde, o hospital é, também, uma sociedade humana que desenvolve sua cultura organizacional e, em consonância com o momento atual, está manifestando a necessidade de sintonizar-se com os novos valores.

Particularmente, os recursos humanos da enfermagem, na sua produção de bens imateriais e nos seus relacionamentos, têm sentido a necessidade de maior conexão e reintegração pessoal no cuidado ao cliente. Em outros termos, tem emergido um anseio por revitalizàção de valores que se encontravam adormecidos. Neste sentido, a liderança da enfermeira encontrará nos valores da pós-modernidade um alicerce compatível com a necessidade sentida, e, então, a ética precisa ser compreendida à luz do paradigma emergente. Assim sendo, nosso objetivo é abordar a liderança da enfermeira sob a ótica dos valores e da ética pós-moderna.

\section{A ENFERMEIRA E A LIDERANÇA REVISITADA}

A inovação tecnológica possui conseqüências não apenas em relação à profissão de enfermagem e à saúde do paciente, mas põe questões contundentes no que respeita à pessoa dos participantes desta relação. É onde urge a necessidade de se refletir sobre a eterna questão do valor da pessoa humana.

A promoção do ser humano em toda sua amplitude é função da enfermeira que exerce liderança. Nessa promoção, a enfermeira integra colaboradores, que juntos, ministrando o cuidado, devem se fundamentar no conhecimento, na competência e ir mais além - na sensibilidade, na solidariedade e no respeito pela dignidade humana.

Nessa linha, Rorty (1995) enfatiza que a solidariedade é algo resultante da imaginação e 
fruto do exercício da sensibilidade. Por profissão e por dever a enfermagem está sempre em contato com o sofrimento alheio. Dessa forma, a enfermeira-líder encontra-se continuamente num ambiente propício para o desenvolvimento desses valores em si mesma e nos integrantes de sua equipe. Ser solidário, para Rorty (1995), é ser sensível à dor e à humilhação.

Parafraseando Maturana e Varela (1995), a enfermeira-líder inserida neste contexto aceita o outro em toda sua plenitude do existir, e o aceita com amor.

Para Touraine (1995), no mundo de hoje - que passa da sociedade industrial para a sociedade pós-industrial, ou sociedade programada como denomina este autor, ao contemplarmos a fusão da racionalização e subjetivação, "o essencial é reconhecer a formação de uma cultura e de novas relações sociais, ligadas à substituição das indústrias materiais pelas indústrias culturais" ( Touraine, 1995, p.264 e 292). Assim sendo, as formas de organização social, as condutas pessoais ou coletivas se transformam e privilegiam a retomada da idéia de sujeito.

Os críticos da modernidade racionalista buscaram uma resposta no resgate ao Ser, entendendo que " é somente na relação ao outro como sujeito, que o sujeito pessoal pode assenhorear-se de si mesmo. É somente quando o outro-sujeito se dirige a mim, a fim de que eu seja sujeito para ele, que eu sou realmente sujeito" ( Touraine, 1995, p.264 e 292).

Essas reflexões nos remetem à liderança da enfermeira junto aos seus clientes internos e externos no contexto do cuidado de enfermagem. Compreendemos que esta liderança poderá se constituir numa experiência central fundamentada na relação ao outro, através da qual um e outro, ou seja enfermeira e cliente, se apresentam como sujeitos. Contudo, seria artificial não considerar que o encontro do outro se dá em um cenário carregado de obstáculos exteriores e interiores.

Desse modo, no seu processo de liderança torna-se necessário que a enfermeira se empenhe no sentido de reconhecer o seu cliente (interno ou externo) como sujeito, participando de seus esforços na luta para se libertar dos obstáculos sociais que o limitam de viver a plenitude, como sujeito. Na busca desse viver e desse encontro, a conduta da enfermeira, configurada a partir do seu ser, e facilitada pela proximidade de seu cliente, deve ser sedimentada na construção da solidariedade e do amor ao outro.

É preciso recuperar o caminho que aponte a relação social na enfermagem fundamentada na solidariedade. É preciso conciliar nesse serviço os valores da estética, da ética, com os valores da técnica e da economia.

A liderança da enfermeira na perspectiva da ética pós-moderna implica no entendimento de que a ética é, antes de tudo, o limite que a própria pessoa impõe a si mesma; exige como base autonomia e responsabilidade.

Num contexto organizacional moderno comumente encontramos a auto-imposição, ou profissionais se dirigindo por normas e leis que seguem mas não aceitam, tornando tais pessoas legalistas, porém não éticas. Já num contexto organizacional pós-moderno, os profissionais requerem espaço para decisão sobre suas ações e suas vidas. A eticidade exige a aceitabilidade do foro íntimo e isto é um requisito singular da sociedade atual: a sociedade do conhecimento, na qual as pessoas devem saber ser autônomas - tenham auto-decisão e valorizem os princípios da diversidade e da interdependência.

Entre vários outros profissionais transitórios, a presença permanente da enfermeira no ambiente hospitalar favorece a conexão e a reintegração dos diversos trabalhos aí desenvolvidos. Nesse caminho, a liderança da enfermeira poderá promover uma mescla de lógicas distintas proveniente do desempenho interdisciplinar provocando, em conseqüência, o despertar da riqueza criativa, estética e ética, tendo em vista o modo-de-ser-cuidado, preconizado por Boff (1999), onde impera a relação sujeito-sujeito.

ABSTRACT: The administrative models arising from modernity are becoming increasingly obsolete in view of the needs of organizations, especially those which provide health care such as health institutions 
and their human capital. Since rationality is an essential element for the accomplishment of organizational objectives, modern ethics requires only that workers adjust to their prescribed functions and perform their tasks according to the rules. Post-modernity is characterized by saturation of information and consumption, pleasure of using goods and services, lack of values and meaning of life, reflecting a post-modern apathy. Without projects man's interior life has no substance. Health organizations are being strongly influenced by this context. Hence, ethics needs to be treated in a new way. Thus, the purpose of this paper is to approach nurse's leadership in light of post-modern ethics.

KEYWORDS: leadership, ethics, knowledge, aesthetics, organizational culture

RESUMEN: Los enfoques administrativos oriundos de la modernidad se están volviendo cada vez más obsoletos frente a las necesidades de las organizaciones, sobre todo de las prestadoras de servicios como es el caso de las instituciones de salud, así como su capital humano. Puesto que la racionalidad es un elemento esencial en la consecución de los objetivos organizacionales, la ética moderna exige apenas que los trabajadores se ajusten a los cargos descriptos y a las normas de desempeño en el cumplimiento de sus tareas. La posmodernidad se caracteriza por la saturación de información y consumo, por el placer de usar bienes y servicios, por la ausencia de valores y de sentido para la vida, todo lo cual refleja la apatía posmoderna. Sin proyectos, la vida interior del hombre es sin sustancia. Las organizaciones de la salud están sufriendo fuertes influencias de este contexto. En ese sentido, la ética se tiene que tratar de manera nueva. Así siendo, nuestro propósito es enfocar el liderazgo de la enfermería bajo la ética posmoderna.

PALABRAS CLAVE: liderazgo, etica, conocimiento, estética, cultura organizacional

\section{REFERÊNCIAS BIBLIOGRÁFICAS}

BOFF, L. Saber cuidar. ética do humano - compaixão pela terra. Rio de Janeiro: Vozes, 1999

CAPRA, F. O ponto de mutação. Trad. Álvaro Cabral. São Paulo: Cultrix, 1995. p. 253.

DE MASI, D. O futuro do trabalho: fadiga e ócio na sociedade pós-industrial. Trad. Yadyr A Figueiredo. 4. ed. Rio de Janeiro: José Olympio; Brasília: UNB, 2000. p.167; p. 183; p. 184.

DE MASI, D. A sociedade pós-industrial. In: DE MASI, D (Org) A sociedade pós-industrial. Trad. Anna Maria Cappovi \& col. 2. ed. São Paulo:Senac, 1999. p.167; p. 183.

FERRAZ, C.A. A transfiguração da administração em enfermagem - da gerência científica à gerência sensivel. 1995. 248p. Tese (Doutorado) - Escola de Enfermagem de Ribeirão Preto, Universidade de São Paulo, Ribeirão Preto, 1995.

MOTTA,P.R. Transformação organizacional: a teoria e a prática de inovar. Rio de Janeiro: Qualitymark, 1997

MATURANA, H.; VARELA, G. A árvore do conhecimento. Campinas: Workshopsy, 1995.

RORTY,R. Contingency, irony and solidarity. Cambridge, New York: Cambridge University Press, 1995. 201p.

TOURAINE, A. Crítica da modernidade. Trad. Elia Ferreira Edel. 3.ed. Petrópolis, Rio de Janeiro: Vozes, 1995. p. $264 ;$ p. 292

Recebido em maio de 2000

Aprovado em outubro de 2000 